\title{
Desafios do cuidado em rede na percepçáo de preceptores de um Pet Redes em relaçáo à pessoa com deficiência e bebês de risco: acesso, integralidade e comunicação
}

\author{
Marta Aoki, Marina Picazzio Perez Batista, Maria Helena Morgani de Almeida, \\ Daniela Regina Molini-Avejonas, Fátima Corrêa Oliver
}

Departamento de Fisioterapia, Fonoaudiologia e Terapia Ocupacional, Faculdade de Medicina, Universidade de São Paulo - USP, São Paulo, SP, Brasil.

\begin{abstract}
Resumo: Introdução: As Redes de Atenção à Saúde (RAS) configuram-se como possibilidade de articular e coordenar ações e serviços, sendo hoje prioridade na organização do sistema de saúde. Considerando a necessidade de seu aprimoramento, o Programa de Educação pelo Trabalho (PET) na saúde é desenvolvido como uma estratégia para tal. Nesse contexto é preciso compreender os desafios e potências para a efetivação da RAS na produção do cuidado em rede. Objetivo: Identificar e analisar as percepções de profissionais preceptores de um PET Redes (Rede Cegonha/Bebês de risco e Rede Cuidado da Pessoa com Deficiência) sobre como se conforma a atenção em rede e sobre possíveis desafios das ações profissionais nessa configuração. Método: Estudo qualitativo, realizado por meio de dois grupos focais com profissionais preceptores de um PET Redes. Resultados: Em ambas as Redes o acesso, o atendimento integral e a comunicação apareceram como categorias da configuração do trabalho em rede. Alguns dos desafios mencionados envolvem: barreiras geográficas e arquitetônicas, falta de apoio social e transporte para deslocamento aos serviços, falhas de fluxos e descontinuidades nos processos comunicativos. Para lidar com esses desafios, foram mencionadas como estratégias: uso de prontuário eletrônico e constituição e participação em fóruns específicos de discussão e articulação de ações, entre outros. Destaca-se que as categorias estão articuladas e que os participantes apontaram mais desafios do que estratégias para superá-los. Conclusão: Os desafios para efetivação das RAS colocam-se em diferentes níveis e a construção de estratégias necessita ser pactuada entre os atores sociais envolvidos.
\end{abstract}

Palavras-chave: Atenção Primária à Saúde, Acesso aos Serviços de Saúde, Assistência Integral à Saúde, Comunicação.

\section{Challenges on network care considering the perceptions of preceptors of a Pet-Network regarding people with disabilities and at-risk infants: access, comprehensiveness and communication}

\begin{abstract}
Introduction: Health Care Networks ( $\mathrm{HCN})$ are seen as a possibility for articulating and coordinating actions and health services and a priority in the health system. One strategy to assure their improvement is the Tutorial Education Program (PET-Redes) in the health area. Within this context, it is important to understand the challenges and strengths for the effectiveness of $\mathrm{HCN}$ in health care. Objective: To identify and analyze the perceptions of professionals who are preceptors of PET-Networks (Stork/at-risk infants Network and Disabled People Network) about the configuration of the care network and the challenges of professional actions. Method: Qualitative study conducted through two focus groups with professionals that are preceptors of the PET-Networks. Thematic analysis
\end{abstract}

Autor para correspondência: Marta Aoki, Faculdade de Medicina, Universidade de São Paulo, R. Cipotânea, 51, Butantã, CEP 05360-160, São Paulo, SP, Brasil, email: aoki@usp.br

Recebido em Dez. 13, 2016; 1ª Revisão em Abr. 24, 2017; Aceito em Maio 25, 2017. 
was used for data analysis. Results: Both networks presented the following categories related to the care network configuration: access, comprehensive health care and communication. For this care network configuration, some challenges mentioned include geographical and architectural barriers, lack of social support, lack of transportation, failure on care flow and discontinuities in the communicative process. To deal with these challenges, the following strategies were mentioned: implementation of electronic medical records and formulation of specific forums for debate and articulation of actions, among others. It is important to notice that these categories are intertwined and that more challenges than strategies to overcome them were pointed out by the participants. Conclusion: There are several challenges for effective HCN from different levels and the construction of strategies needs to be convened among all persons involved in the $\mathrm{HCN}$.

Keywords: Primary Health Care, Health Service Accessibility, Comprehensive Health Care, Communication.

\section{Introdução}

Os sistemas de saúde no mundo têm sido tradicionalmente orientados para responder às condiçôes agudas (PAN...; WORLD..., 2007; MENDES, 2011; SILVA, 2011), enquanto as principais demandas em saúde na atualidade se relacionam ao cuidado de condiçốes crônicas. Essas condiçôes devem ser equacionadas pela constituição de Redes de Atenção à Saúde (RAS) (MENDES, 2011), apontada como estratégia privilegiada para superar a fragmentação da atenção e da gestão em saúde (BRASIL, 2010).

As RAS são definidas como arranjos organizativos de açôes e serviços de saúde, de diferentes densidades tecnológicas que, enquanto pontos de atenção em saúde, devem ser integrados por meio de sistemas de apoio técnico, logístico e de gestão, buscando garantir assistência contínua e integral a uma populaçáo definida (BRASIL, 2010; MENDES, 2011). Nesse sentido, as Redes de Atenção à Saúde orientam-se para responder ao desafio, enfrentado pelo Sistema Único de Saúde (SUS) desde sua criação, de promover uma melhor integração entre os serviços e as açóes de saúde. Destaca-se que um ponto de atenção essencial da RAS é a Atenção Primária em Saúde (APS), por sua responsabilidade de reconhecer e responder a maior parte das necessidades de saúde de sua população e de coordenar o seu cuidado em saúde em outros pontos de atenção e no território (MENDES, 2011; STARFIELD, 2002).

A implementação das RAS foi a principal diretriz da Secretaria de Atenção à Saúde (SAS) para o período de 2011 a 2014, quando foram priorizadas a constituição e implantação de cinco redes temáticas, dentre elas, a Rede Cegonha (RC) (BRASIL, 2011) e a Rede de Cuidado à Pessoa com Deficiência (RPCD) (BRASIL, 2012, 2014). A RC visa assegurar à mulher o direito ao planejamento reprodutivo e à atenção humanizada à gravidez, ao parto e ao puerpério; bem como à criança, o direito ao nascimento seguro e ao crescimento e desenvolvimento saudáveis (BRASIL, 2011). A RCPD objetiva ampliar o acesso e qualificar o atendimento das Pessoas com Deficiência $(\mathrm{PcD})$, promover sua vinculação e de suas famílias aos pontos de atenção e garantir a articulação e a integraçáo dos pontos de atençáo, qualificando o cuidado por meio do acolhimento e classificação de risco (BRASIL, 2012, 2014).

Apesar da potência colocada no trabalho no âmbito das RAS, muitos fatores têm dificultado sua gestão, como a diversidade de atores envolvidos e de organização de serviços da APS, a escassez de serviços de atenção secundária e terciária e as dificuldades de controle e coordenação das interdependências (MENDES, 2010). Considerando esse cenário, buscou-se compreender por meio de um Programa de Educação pelo Trabalho (PET) na saúde com temática sobre Redes de Cuidado em Saúde (PET Redes USP Capital), como se conforma a atenção em rede no território da Supervisão Técnica de Saúde do Butantã (STS-BT) e sobre quais são os possíveis desafios das ações profissionais nessa configuração, buscando contribuir para a implementação e a qualificação das RC e RPCD. Vale ressaltar que o PET Redes é um programa concebido e fomentado pelo Ministério da Saúde que visa desenvolver e aprimorar as RAS em âmbito nacional. Para o alcance dessa finalidade, o PET Redes promove, por meio de grupos de aprendizagem e de tutoria, a integração ensino-serviço-comunidade, a qualificação dos profissionais para trabalharem em conformidade com os princípios do SUS, a formação de profissionais voltada à atenção integral à saúde da população e ao trabalho interprofissional e fomenta pesquisa sobre o tema (BRASIL, 2013).

Buscando contextualizar o cenário em que se desenvolveu o trabalho, é importante assinalar que o PET Redes mencionado foi desenvolvido entre 2013 e 2015 no território da STS-BT visando qualificar especificamente as RC e RCPD na STS-BT, sendo uma parceria entre a Universidade de São Paulo e 
serviços de saúde do Butantã. Os grupos tutoriais PET/RC e PET/RCPD desenvolveram diversas açôes que incluíram levantamento de informaçóes sobre $\mathrm{PcD}$ e bebês de risco na regiāo, acompanhamento e participação em açôes interprofissionais e intersetoriais voltadas a essas populaçôes.

Vale assinalar que a RC foi escolhida pois, apesar da existência de um conjunto de serviços para acompanhamento e enfrentamento das situaçóes de risco e de uma comissão de acompanhamento de bebês em risco de reconhecida competência técnica, ainda é frágil a articulação entre serviços na regiáo. Assim, a opção de abordar o bebê de risco deu-se com base no diagnóstico territorial de saúde, em que, apesar do coeficiente de mortalidade infantil no Butantã ter se reduzido (10,3 para 7,6), sabe-se que as condiçôes de saúde de bebês de risco também podem contribuir para a composição desse coeficiente. Nesse contexto, gestores da regiấo verificaram a necessidade de buscar ativamente os bebês de risco da regiấo e determinar os fluxos do cuidado e conhecer possíveis nós da Rede Cegonha, que preconiza o acompanhamento do desenvolvimento do bebê de 0 a 24 meses. Desta forma, sugeriram que o PET-Redes priorizasse essa população em detrimento das gestantes. Já no caso das RPCD, a despeito da importância da problemática e da existência de serviços, estes não contemplam integralmente as demandas dessa populaçấo. Destacam-se ausência de informaçóes específicas sobre atenção ao grupo, grande heterogeneidade das competências técnicas dos profissionais, falta de infraestrutura, de diretrizes de atenção e insuficiência da articulação entre os serviços de saúde, transporte e assistência social (SÃO PAULO, 2013a). Desde 2015, a RPCD tem sido acompanhada na região por comissão específica.

É nesse contexto que se inscreve este estudo, que objetivou identificar e analisar as percepções de preceptores sobre a conformação da atenção em rede e os desafios e potências para a efetivação da RAS na produçấo do cuidado em rede a partir do desenvolvimento de um PET Redes.

\section{Método}

Este estudo foi parte integrante de uma pesquisa mais abrangente denominada "Atenção Básica como ordenadora das redes de atenção à saúde Cegonha e de Cuidados à Pessoa com Deficiência", fomentada pela FAPESP, que também compôs o Programa PET Redes USP Capital, apoiado pelo Ministério da Saúde por meio de concessáo de bolsas para tutores, preceptores e estudantes de graduação. Foi desenvolvido na Coordenadoria Regional de Saúde Centro-Oeste (CRS-CO), Supervisão Técnica de Saúde/Butantã (STS/BT), da Secretaria Municipal de Saúde de São Paulo, por meio de parceria entre pesquisadores da Universidade de São Paulo (USP), profissionais de parte dos serviços da região e estudantes. Foi aprovado pelo Comitê de Ética da Secretaria Municipal de Saúde de São Paulo e Comitê de Ética da Faculdade de Medicina da Universidade de São Paulo. Os serviços participantes do PET Redes foram escolhidos em acordo com a Coordenadoria Regional de Saúde Centro Oeste - CRSCO e STS/BT por sua articulação com a APS e por já desenvolverem atividades de ensino e realizarem açôes relacionadas à RC e/ou RPCD. Os preceptores de ambas as Redes foram indicados pelos serviços/gestores de cada unidade por sua experiência e vinculação às atividades relacionadas às Redes, sendo 6 preceptores para a RC e 6 para a $\mathrm{RPCD}$, totalizando 12 profissionais.

Neste artigo seráo apresentados e discutidos os resultados referentes a uma destas etapas da pesquisa, caracterizada como qualitativa, exploratória e descritiva, que foi realizada por meio da constituiçáo de dois grupos focais, um para cada rede de atenção. Os participantes convidados foram os preceptores dos serviços que compuseram a RC e RCPD, por sua vinculação anterior. Assim, participaram do estudo, quatro profissionais da RC e seis profissionais da RCPD. Em relação à distribuição por serviços, três eram representantes de NASF, um de UBS com ESF, dois de hospitais, um de CECCO, um de ambulatório de especialidades e dois supervisores das redes.

A escolha pelo método do grupo focal se deu porque este se configura como uma ferramenta de pesquisa que facilita a compreensão de processos menos visíveis e que permite destacar, em grupo, aspectos inexplorados a respeito de uma questáo específica. Possibilita, também, acessar significados e conceitualizaçóes dos participantes sobre o tema em discussão e favorecer a exploração de suas perspectivas sobre questões para as quais não havia reflexão anterior (BARBOUR, 2009).

Os grupos focais ocorreram ao final do processo do PET Redes, pois se compreendeu que estes se configurariam como potencial espaço de diálogo entre profissionais de diferentes serviços. Os grupos foram realizados em duas sessóes para cada uma das redes de atenção. Na RPCD participaram cinco profissionais e seis na segunda sessão. $\mathrm{Na} \mathrm{RC}$ participaram quatro profissionais na primeira sessão e um profissional na segunda sessão. Essa variação de presença pode ser explicada por imprevistos vivenciados pelos participantes. Destaca-se que, 
tendo-se em vista a baixa adesão na segunda sessão do grupo focal da RC, foram considerados apenas os resultados apresentados na primeira sessão para essa rede de atenção.

As duas sessóes dos dois grupos focais de cada uma das redes foram conduzidas separadamente, em julho de 2015, no Departamento de Fisioterapia, Fonoaudiologia e de Terapia Ocupacional da USP/SP e a duração de cada sessão foi de duas horas. A condução dos grupos focais das duas redes foi realizada por um moderador principal com experiência na condução de grupos focais e não envolvido com o PET Redes, e por moderadores assistentes (um terapeuta ocupacional e um bolsista de capacitação técnica, ambos participantes do PET Redes, mas náo inseridos na rede do grupo focal); os moderadores assistentes, por compreenderem o processo de pesquisa e da proposta do PET Redes, auxiliaram o moderador principal com informaçôes a fim de melhor conduzir o grupo.

Para desenvolvimento dos grupos focais das duas redes foi utilizado um mesmo roteiro que buscou compreender, considerando a conformaçáo das RC e RPCD na STS/BT, quais açóes e estratégias os participantes proporiam para potencializar as redes em que estáo envolvidos. As sessôes de cada um dos grupos focais foram iniciadas por uma questão disparadora, a fim de favorecer a discussão sobre o tema específico de pesquisa. A questão disparadora da primeira sessão do grupo focal das duas redes foi: "Quais ações são realizadas atualmente em seu serviço para o trabalho em rede de atenção para crianças até dois anos e/ou adolescentes e/ou adultos e/ou idosos com deficiência na STS Butantâ?" No caso da segunda sessão do grupo RCPD, a pergunta disparadora foi: "Você identifica um caso emblemático envolvendo criança e/ou adolescente e/ou idoso assistido em serviço que compóe a STS/BT, que mobilizou o trabalho em rede de atenção em saúde?"

Todos os participantes assinaram termo de consentimento livre e esclarecido e as sessóes foram gravadas e transcritas. A identificação dos profissionais e suas intervençóes foram realizadas alfanumericamente (P1: profissional 1) e pela rede que participam através de letras que as representavam (RC e RPCD).

Foram realizadas pré-análise, exploração do material, tratamento dos dados obtidos e análise temática, conforme etapas descritas por Minayo (2007). Considera-se que a análise temática permitiu tratamento qualitativo apropriado aos dados coletados nas sessões do grupo focal de ambas as redes. A análise temática possibilitou a identificação das seguintes categorias: acesso, integralidade e comunicação. Essas categorias tratam da conformação do trabalho em rede e é a partir dessas categorias que se colocam os desafios e potências do trabalho em rede, apontados pelos participantes do estudo. Tendo em vista o entrelaçamento entre as três categorias temáticas, optou-se pela apresentação dos resultados dessas categorias conjuntamente, apenas diferenciando os resultados de cada uma das redes de atenção.

\section{Resultados}

\subsection{Rede Cegonha/Bebês de risco: acesso, atendimento integral e comunicação}

Primeiramente, os profissionais assinalaram a existência de uma diferença no acesso e no acompanhamento do bebê e da gestante de risco entre os serviços que se constituem como Unidades Básicas de Saúde (UBS) tradicionais e as que contam com a Estratégia de Saúde da Família (ESF). Identificam que esta diferença reside especialmente na possibilidade das equipes com ESF realizarem busca ativa, enquanto, nas unidades tradicionais o acesso, o acompanhamento e a gestáo do cuidado dependem das próprias famílias, o que pode levar à ausência nas atividades organizadas pelo serviço.

Em relação às dificuldades na construçáo de um trabalho integral, os profissionais assinalaram que há uma desarticulação entre os serviços do território, o que acarreta isolamento de açóes e dificulta o trabalho em rede. Os profissionais também consideraram que, ainda que os serviços mantenham contato, há conflitos no entendimento do que seria a necessidade de saúde do usuário e os possíveis encaminhamentos para o atendimento de suas necessidades, o que dificulta a criaçáo de uma rede entre os serviços:
P1RC: [...] quem acompanha, [...] a rede de apoio, é a UBS. E nem sempre esses dois serviços se conversam (hospital e UBS). E quando se conversam, sai faísca. Porque [...] várias vezes algumas equipes (ESF) voltaram de reuniāo [...] e falaram assim [...] as pessoas não entendem $o$ que éessa familia, essa rede de apoio. A gente quer fazer isso, mas eles não querem liberar o bebê [...]. Acho que conhecer a prática do outro, conversar e talvez confiar no trabalho das duas partes.

A dificuldade no estabelecimento de uma rede entre os serviços também está presente nas diferentes percepçôes sobre a condição de "bebê de risco". Discutiram que distintos critérios são utilizados pelos equipamentos para a caracterização desta população: 
P1RC: [...] cada um vai entendo uma situação de bebê de risco de uma forma diferente [...] a supervisáo técnica de saúde considera bebê de risco abaixo de 2,5 kg, mãe menor de 16 anos, apgar abaixo de 5 no primeiro minuto [...]. As ESF, cada uma a partir da sua realidade de território, considera a sua gestação de risco, o bebê de risco por esses critérios e por alguns outros, então: vulnerabilidade, rede da família nuclear, rede de apoio da familia, condição socioeconômica.... As equipes váo incluindo ou excluindo critérios de risco.

Segundo os participantes, a diferença de compreensão do que seria um bebê de risco influencia diretamente o trabalho em rede. Quando um serviço encaminha um bebê que considera ser de risco para acompanhamento em um outro que náo tem a mesma compreensão, este bebê pode tanto não ser considerado de risco como não receber atendimento prioritário.

Os profissionais também assinalam que há importantes problemáticas em nível de comunicação:

P1RC: [...] o que eu identifico como principal nó. Os serviços eles não se conversam.

Refletiram sobre diversos motivos para a falta de comunicação e consideraram que uma das razóes seria as distintas concepçôes entre os serviços da rede sobre critérios para considerar um bebê como sendo de risco. Ainda relataram o excesso de demandas nos serviços, o que dificulta participar de reunióes com profissionais em outros equipamentos de saúde, favorecendo o isolamento no próprio serviço.

Outra questáo apontada foi que frequentemente os fluxos estabelecidos entre os serviços são bastante dependentes e centrados em determinados profissionais:

PIRC: [...] depende da boa vontade do profissional que está conduzindo o caso em mandar individualmente para o outro, que às vezes é até no e-mail pessoal.

Neste sentido, quando um profissional de referência para determinado processo ou gestão do cuidado, por algum motivo, deixa de trabalhar no serviço, este é interrompido:

P1RC: Quando os serviços se conversam, ficam focados na figura de um profissional [...] e isso é muito ruim, porque se o profissional sai, vocêp perde o vinculo, o acesso àquela equipe, às informaçōes.

P3RC: Se ela sai de férias, se aposenta, você perde suas informaçōes.

Os participantes assinalaram que muitas vezes o usuário se apresenta para atendimento sem o histórico e as queixas de saúde identificados nos demais serviços da rede. A dificuldade de comunicação acaba por lentificar a identificaçáo das demandas e necessidades do usuário, o que influencia na prestação de atendimento. Citaram, por exemplo, a demora da equipe hospitalar em identificar o histórico de uso de álcool e drogas em gestantes de risco, já anteriormente atendidas pela UBS, que previamente teria o conhecimento destas informações:

P3RC: A história dessa gestante às vezes nunca chega para gente. Demoramos um tempão para descobrir que é uma gestante que tem um risco [...] sendo que muitas vezes a UBS já sabia e era só ter mandado para nós.

Ainda, foram mencionadas as dificuldades na comunicação no que diz respeito a fluxos entre serviços previamente acordados:

P1RC: Tem um fluxo oficial? Teoricamente tem, mas eu não sei o que acontece que as pessoas não seguem [...] náo usam o papel de referência e contra referência [...] tem que seguir esse fluxo, independente das pessoas.

Também afirmaram que, com grande frequência, os profissionais direcionam o formulário aos serviços, porém com pouca ou nenhuma informação sobre o usuário e sua família, o que não permite o conhecimento do histórico e das necessidades dos mesmos:

P1RC: As pessoas colocam: 'à UBS’. Mas, ‘à UBS' fazer o que? [...]. Qual a história dessa família?

Justamente por identificarem essas questóes como problemáticas no processo de cuidado dos usuários, os profissionais fizeram apontamentos sobre a maior qualidade que tem os encaminhamentos realizados com a passagem de informaçóes relevantes sobre os usuários e sobre as possíveis vantagens de fluxos oficiais, de maneira a garantir a participação de todos os serviços:

P3RC: Há uns anos atrás teve relatório [...] e foi muito produtivo, porque o paciente chegou e a gente já sabia como conduzir o caso [...] a gente conseguiu trabalhar muito rapidamente.

Contudo, discutiram que, mesmo com tais ações, não é garantido que o histórico de determinado usuário seja acessado pelos serviços e apontaram o prontuário eletrônico como uma possibilidade para favorecer a comunicação:

P4RC: [...] no prontuário, todo mundo vai ter acesso à informação. 
Tratando dos desafios de tal proposta, foi mencionado que o prontuário eletrônico pode não auxiliar na comunicação de informaçóes com o hospital, visto que se prevê que esse equipamento náo teria acesso ao mesmo. Neste sentido, discutiram sobre o envio de informaçôes por correio eletrônico, acordando que este envio deveria ser realizado institucionalmente e não pelos endereços particulares dos profissionais. Ressaltaram que esta medida demandaria que os serviços criassem um fluxo para chegada de informações, com açôes que garantissem que estas fossem acessíveis aos profissionais daquele equipamento.

Outra questão relacionada à comunicação refere-se à dificuldade de envio de informaçóes de alguns serviços hospitalares para a STS/BT especialmente no que tange ao nascimento de bebês de risco. Os profissionais relataram que quando este fluxo oficial de comunicação do hospital para a STS/BT não é seguido, não é possível que esta sinalize para a UBS que há um novo bebê de risco naquele território. Neste sentido, a busca pelo atendimento no território pós-alta hospitalar fica somente sob a responsabilidade da família, que não necessariamente comparece ao serviço. Discutiram que esta ruptura impede o acompanhamento deste bebê na rede de serviços de saúde.

A informatização do sistema e/ou outros mecanismos de comunicação permitiriam a sinalização, para o território, que o bebê é de risco, o que favoreceria sua identificação e consequentemente o agendamento de sua consulta, especialmente nas UBS tradicionais. Sugerem a criação de algum código sinalizador que pudesse ser incluído nos próprios códigos gerados pelo sistema, como por exemplo, colocar a palavra risco junto ao nome do bebê:

P4RC: [...] a gente tem que buscar alternativas lá no $S I G A^{I}[\ldots]$ de repente criar um código depois com o nome do bebe.

Sugeriram também que se criasse um fluxo dentro da UBS que separasse todos os prontuários dos bebês de risco a fim de verificar facilmente o agendamento de sua consulta. Ressaltaram ainda que esta sinalizaçáo impulsionaria a busca ativa no território quando o bebê não comparece à consulta:

P4RC: [...] sinaliza que é risco e a UBS se organiza de uma forma que, por exemplo, separa os prontuários dos bebes de risco [...] porque quando tem consulta e não veio, tem que fazer busca ativa.

Para facilitar a comunicação entre os serviços, refletiram, também, sobre a necessidade de institucionalização de espaços de discussão e, mesmo assim, identificaram que apenas tais espaços podem não ser suficientes para a comunicação entre os serviços:

P1RC: [...] espaços de encontro? [...] mas teriam que seguir um fluxo que seja oficial. Porque também se fica nos encontros, fica focado nas pessoas que vão nesses encontros.

\subsection{Rede de Cuidados da Pessoa com Deficiência: acesso, atendimento integral e comunicação}

Considerando a APS como porta de entrada do sistema de saúde, foi discutido que o acesso de $\mathrm{PcD}$ pode estar dificultado por uma representaçáo social do papel da APS e por suas diferentes formas de organização em modelos de gestão como a UBS tradicional e as que contam com ESF:

P4RPCD: Em uma UBS tradicional [...] muitas pessoas não chegam ao serviço porque nem a família entende aquele serviço como de cuidado à $P c D$ ou a própria unidade não entende que ali é um espaço de cuidar daquela pessoa [...] você tem um modelo (ESF) que faz a busca ativa, isso não garante o acesso, mas o fato de você olhar para o território [...] faz toda a diferença.

Também foram apresentadas as dificuldades de acesso no território, especialmente para as pessoas com mobilidade reduzida. Os participantes identificaram problemas de acessibilidade nas moradias, nas ruas, nos serviços e no transporte público.

Ainda, os profissionais relatam que a dificuldade no acesso está também relacionada aos critérios de elegibilidade restritos para o usufruto tanto de serviço de transporte adaptado como dos serviços de saúde e reabilitação:

PGRPCD: E os cadeirantes? Além de ter essa dificuldade ele precisa do ATENDE 2 [...] Como ele vai ser conduzido até a sua unidade? (...) tem toda uma burocracia [...] ele tem que estar em tratamento [para ter direito ao ATENDE].

P5RPCD: [...] paciente logo depois de um AVE [...] mobiliza as equipes [...] depois de um tempo que a questão fica crônica [...] não entra no protocolo.

Além disso, os profissionais argumentam que o acesso ao serviço também depende da existência de uma rede social de apoio, composta por familiares, vizinhos e serviços comunitários:

P4RPCD: [...] porque mesmo que consiga os serviços na rede, não vai conseguir acessar [...]. 
Acho que tem que mobilizar mesmo uma rede de apoio [...]. Tem uma rede local ali que você pode articular, ou é a familia, um vizinho.

Em relação às propostas para lidar com as dificuldades de transporte e deslocamento das pessoas com mobilidade reduzida pelo território, foram citadas a otimizaçáo do uso do serviço ATENDE, campanhas no bairro, como, por exemplo, "carona do vizinho", e negociaçôes junto ao poder público. Nestas negociaçóes sugerem, por exemplo, que uma van pudesse circular entre os serviços de saúde para facilitar o acesso.

Sobre o atendimento integral, discutiu-se a importância de se compreender a complexidade das necessidades da PcD para se pensar no projeto terapêutico do sujeito e sua família:

P1RPCD: [...] pensar a PcD não é a partir da patologia, mas da sua condição, da sua necessidade [...] cuidar das condiçôes minimas de vida [...] uma ação de reabilitação pensando na PcD no território, na sua condição de vida mais global.

Na elaboração do projeto terapêutico em rede, é necessário compreender também o sujeito e sua família como protagonistas de todo o processo de intervenção:

P4RPCD: [...] é um desafio como você dimensiona no projeto as necessidades do outro, que seja centrada no desejo do outro [...], mas que também sejam consideradas as necessidades que a gente vê de risco [...] um projeto terapêutico que considere [...] o que a gente entende que é prioridade clínica, com o que ele e a máe definem como prioridade.

Os profissionais destacaram, ainda, a importância da construção de um trabalho com a articulação de diferentes profissionais e serviços de modo a atender às necessidades reais do sujeito em cada momento de sua vida. Destacaram a relevância da responsabilidade longitudinal sobre o acompanhamento do usuário da rede para favorecer a integralidade do cuidado.

Apontaram, também, que os fluxos de informaçôes e de atendimento náo estão claros para profissionais e usuários, pois, segundo os mesmos, há dificuldade para compreender os caminhos corretos para acesso aos diferentes serviços.

Em situaçóes de vulnerabilidade social vivenciadas de forma mais marcante pelas $\mathrm{PcD}$, os profissionais relatam que os fluxos estabelecidos tendem a ser menos eficientes e apontam estratégias para facilitar o acesso:

P3RPCD: [as PcD não acessam os fluxos] tanto quanto a gente gostaria, então dai fica a cargo dos nossos atendimentos, das visitas domiciliares, para a gente alcançar esse público.

Além disso, foi discutida a ampliação da oferta de serviços e atividades para além do ponto de atenção e de acordo com as necessidades das PcD. Para tanto, o conhecimento das propostas realizadas pelos diferentes profissionais e serviços da rede pode facilitar o encaminhamento e acesso do usuário, conforme suas múltiplas necessidades. Nesta proposta, os grupos e açôes já disponíveis nos serviços seriam oferecidos a todas as $\mathrm{PcD}$ que necessitam e não só para aquelas da área de abrangência do próprio serviço.

Os profissionais identificaram-se também como articuladores da rede de cuidado, porém apontam para a dificuldade no desenvolvimento das ações no território pela redução do número de profissionais nos serviços. Outra questáo se refere às rupturas e desafios identificados no processo de comunicação. Neste aspecto, mencionam a dificuldade da compreensão acerca do papel de cada serviço na composição da rede, além do fato da rede muitas vezes ser tecida entre profissionais específicos e não por fluxos oficiais estabelecidos entre os diferentes serviços.

Foi mencionado que a frágil compreensão sobre o papel dos profissionais nos diferentes serviços que compóem a rede de cuidado das pessoas com deficiência é um elemento que dificulta a comunicação. Assinalaram que seria importante existir diretrizes para nortear o trabalho do profissional nos diferentes níveis de cuidado e para ampliar a compreensão sobre os diferentes papéis profissionais:

P2RPCD: Só dá para saber esse papel se a gente souber [...] qual a concepção que se tem no município do que é esperado para esses profissionais.

Os profissionais também ressaltam que na APS há protocolos e fluxos mais consolidados em algumas linhas e redes de cuidado e para a assistência às populaçôes tradicionalmente atendidas no nível local. Porém, no campo da reabilitação da PcD há necessidade de construir e pactuar caminhos e fluxos que, muitas vezes, dependem do perfil e disponibilidade do profissional responsável por determinado atendimento:

P2RPCD: [...] a rede [...] que a gente cotidianamente faz [...] é uma rede que não está instituída [...]. Depende dessa articulação muito pessoal, que depende da disponibilidade, vontade que aquilo aconteça [...]. Às vezes a pessoa tem vontade, mas não tem agenda, eflexibilidade de gerências para liberar profissionais para discutir casos. 
Contudo, a comunicação entre profissionais também foi compreendida como potente para a responsabilização pelo cuidado do usuário, sobretudo a partir do serviço de atenção primária, como ordenador da rede de assistência:

P4RPCD: A comunicação éum esforço [...] que vai muito mais da APS, onde quem primeiro chega, quem está mais próximo do caso [...]. Então, a gente tem esse papel de: 'vamos ligar!'.

Também apontaram as possibilidades de estabelecimentos de protocolos e fluxos para a melhoria da comunicação. Contudo, problematizam que tais protocolos devem ser flexíveis, considerando a complexidade do trabalho em rede e necessidades dos usuários, que muitas vezes não são contemplados por fluxos assistenciais predefinidos.

Ainda, segundo percepção dos participantes, existe, entre os profissionais da rede, certa dificuldade em encaminhar usuários para outros serviços que não façam parte da rede direta de referência, o que foi chamado pelos profissionais como "apego aos seus usuários":

P2RPCD: As pessoas se apegam '[...] é meu paciente, eu tenho que dar conta de tudo aqui na minha unidade [...]. Mas esse apego que temos ao paciente tem que ser desconstruido. Como é que você vai levando os pacientes para circularem dentro da rede também.

Uma das estratégias para superação dos desafios foi a existência de um fórum de discussão, que possibilite o diálogo entre os serviços da rede, promova o trabalho articulado entre os profissionais e serviços, a discussão coletiva de situaçôes de saúde e reabilitação da populaçáo e viabilize o acompanhamento dos usuários nos diversos pontos de atenção da rede.

Nestes espaços, são discutidas estratégias diversificadas de cuidado, organizaçáo da demanda e os fluxos assistenciais da rede, além de ser um espaço que busca promover mecanismos de formação permanente dos profissionais. No entanto, os profissionais reconhecem que há muitos desafios para se estabelecer uma comunicaçáo institucional mais efetiva:

P4RPCD: [...] fórum é um passo importante [...]. A gente se conhece, pactua, conversa, mas acho que essa coisa tinha que ser além da gente [...] como a gente faz para que, aquilo que a gente pactua no fórum [...] seja das unidades.

Foi assinalado que a construçâo do trabalho em rede também depende de pactuaçôes institucionais entre serviços e suas gerências e entre diferentes secretarias relacionadas às questóes das $\mathrm{PcD}$.
P4RPCD: Como que a gente sai da esfera pessoal para [...] empoderar o serviço. Acho que ai os gestores têm uma importância fundamental [...] porque a nossa governabilidade é restrita.

Neste sentido, a participação social de profissionais e PcD nos espaços políticos foi discutida como meio fundamental para dar visibilidade às necessidades da população e para reivindicar açóes necessárias para promover a melhoria da qualidade da atenção. A participação política é um desafio para todos, algo que ainda está em processo de construção:

PIRPCD: [...] a gente tem que [...] ocupar mais os espaços também politicos, nós e as $P c D$ no território [...] vamos criar espaços de encontro entre as $P c D$ [...]. Que talvez seja o jeito de entender o que se deseja a partir deles mesmos.

\section{Discussão}

\subsection{Acesso, integralidade e comunicação nos processos de cuidado}

Considerando ambas as redes, em relação ao acesso ao sistema de saúde, foram apontados como desafios para a produçáo do cuidado e do trabalho em rede os acidentes geográficos e a arquitetura do território, a falta de apoio social para deslocamento até os serviços de saúde, as diferenças organizacionais e de elegibilidade nos serviços que se constituem como UBS tradicionais e os que contam com a ESF e os restritos critérios para utilizar transporte adaptado e para acessar os serviços de saúde.

A principal questáo do acesso apontada pelos participantes refere-se à mobilidade, em particular para a RPCD. Essa problemática é anterior até mesmo à chegada ao serviço e envolve adaptaçáo do território e da moradia, apoio social, disponibilidade de transporte adaptado, dentre outras necessidades. Os profissionais indicaram açóes locais para lidar com essas dificuldades, tais como incentivar ou construir redes de apoio social ou fomentar alternativas locais de transporte. Vale afirmar que o tema da acessibilidade arquitetônica do território tem sido debatido por muitos autores (SANTARPIO et al., 2015), com destaque para os desafios envolvendo o acesso aos serviços de saúde (KASSOUF, 2005; SOUZA; ROCHA, 2010; CASTRO et al., 2011; AMARAL et al., 2012). Destaca-se também que a legislação sobre o tema ainda não tem conseguido garantir a mobilidade de grande parte da população com limitação em sua locomoção, principalmente nas regiōes periféricas dos municípios. 
Ainda no que tange ao acesso, os resultados mostraram dificuldades relacionadas a distintos entendimentos sobre assistência em reabilitação a bebês de risco e $\mathrm{PcD}$. Em relação às $\mathrm{PcD}$ em particular, a cultura ainda presente de que só podem ser atendidas em serviços de reabilitaçáo também foi considerada como barreira de acesso. Assim, para que as PcD tenham como primeiro contato os serviços de APS é necessário, primeiramente, a superação da ideia, tanto da comunidade como dos profissionais, de que as $\mathrm{PcD}$ têm que ser atendidas exclusivamente em serviços especializados em reabilitação. Alguns autores discutem a necessidade de mudança dessa visão (ALMEIDA, 1997; SOUZA; ROCHA, 2010).

Para Starfield (2002), acesso/acessibilidade envolve a organização do serviço de APS para atender as pessoas que lhe procuram e como o usuário percebe esse acesso. De todo modo, a APS foi considerada porta de entrada que facilita o acesso ao SUS, principalmente pelos modelos de atenção que contam com ESF, o que possibilita realizar visitas domiciliares e busca ativa das pessoas das áreas de abrangência dos serviços. Especificamente sobre a questão da elegibilidade, vale notar que os protocolos de acompanhamento de usuários são definidos, em grande parte, por critérios clínicos relacionados aos quadros agudos de adoecimento, determinados a partir de patologias e por fases iniciais de instalação de processos de dor e incapacidades. Muitas vezes, nessa dinâmica, os processos e seus protocolos podem restringir o cuidado dos sujeitos que não atendem aos critérios.

Mendes (2010) aponta a necessidade de revisão dos modelos voltados exclusivamente para atendimento das condiçôes agudas, enfatizando a relevância da abrangência de intervençóes desde o nível de prevenção em saúde voltada à população geral até àquelas voltadas aos usuários com condições crônicas muito complexas que demandem a gestão de caso. Marsiglia (2012) afirma que os principais aspectos que concernem à acessibilidade seriam a capacidade de adaptação do serviço às necessidades diferenciadas dos usuários, a preocupaçáo com o estabelecimento de equidade e as rotinas e protocolos preocupados com a inclusão.

Nesse sentido, para a constituição de uma rede efetiva, seria interessante que o conjunto de necessidades de cuidado dos sujeitos fosse avaliado e debatido nos serviços, que a oferta de atendimento fosse organizada e os recursos potencializados em direção ao cuidado que considere as diferentes situaçôes e condiçõos de gestantes, bebês de risco e PcD habitantes do território, na perspectiva do atendimento integral.
Entendida como um princípio do SUS e orientação da Organização Mundial de Saúde, a integralidade considera a relevância de serviços adequados às demandas singulares do sujeito (WORLD..., 2008). Implica também na articulação de ações entre serviços e programas e na compreensão do usuário a partir da complexidade de suas necessidades reais (MATTOS, 2001; STARFIELD, 2002).

A compreensão das situaçóes de vida dos sujeitos abrange suas necessidades de saúde e também as situaçôes de vulnerabilidade, as redes sociais e de apoio, a condição socioeconômica, dentre outros elementos. Foi apontado, por exemplo, que as necessidades das PcD devem ser compreendidas para além da patologia e que o trabalho em rede deve ter como objetivo a ampliação da autonomia e da participação social das PcD a partir da elaboração do projeto terapêutico, em que o profissional compreende o sujeito e sua família como protagonistas de todo o processo de intervenção e se responsabilizam por seu cuidado. Muitos autores discutem que as necessidades das $\mathrm{PcD}$ estão relacionadas à manutenção da vida e ao acesso a direitos, sendo muito presente a vivência de processos de exclusão social (PIMENTEL et al., 2011; SOUZA; GOMES; AOKI, 2012; AOKI; OLIVER, 2013; SOUZA; PIMENTEL, 2012). Nessa linha, Othero (2010) afirma que as necessidades identificadas pelas $\mathrm{PcD}$ incluem aspectos específicos da assistência em saúde, mas também englobam outras dimensóes como o acesso, os direitos, o trabalho e o lazer indicando a importância de açóes integrais e intersetoriais.

Além disso, os resultados apontam para a existência de problemas nos fluxos de atenção entre os serviços da rede, que muitas vezes não são precisos - em particular, na articulação entre a APS e a atenção hospitalar - e tendem a ser centrados em determinados profissionais, o que pode ocasionar a interrupçáo do cuidado. Ainda vale notar que os temas do acesso e da integralidade são inter-relacionados, pois se os critérios de elegibilidade e compreensão de necessidades são restritos ou confusos pela interrupção do fluxo, não apenas o acesso ao serviço fica limitado, mas a integralidade de açôes entre serviços náo ocorre. Por fim, indicaram como problema a redução e a falta de profissionais para atender as necessidades dos usuários das redes e o baixo conhecimento destes profissionais em relação às ofertas de açôes e recursos dos diferentes serviços.

O investimento na contratação de recursos humanos e de capacitação para atuação no SUS, no âmbito da APS e em trabalho em equipe, têm sido apontado como um dos grandes desafios para efetivar o trabalho em redes de atenção (GONÇALVEZ et al., 2014; 
SHIMIZU, 2013). Importante, também, assinalar que as Linhas de Cuidado, embora não citadas pelos profissionais, são protocolos de cuidado em rede, que buscam delinear alguns fluxos. Estas são propostas que buscam facilitar a comunicação entre as equipes e serviços, programas, açōes e padronizar determinados recursos, em resposta às necessidades epidemiológicas de maior relevância, assim como coordenar a assistência longitudinalmente e conectar papéis e tarefas dos diferentes pontos de atenção e dos profissionais. As Linhas de Cuidado pressupóem uma resposta global dos profissionais envolvidos no cuidado, superando as respostas fragmentadas (BRASIL, 2010). Vale ressaltar que essa necessidade de respostas mais integradas foi identificada pelos profissionais participantes do estudo.

Enquanto estratégias, os participantes trataram da possibilidade de acessar a STS para lidar com casos considerados mais complexos. Ainda, afirmaram a necessidade de oferta dos serviços a partir de um fluxo no território mais ampliado; nesse sentido, um grupo de acompanhamento de usuários realizado em determinado ponto de atenção poderia ser acessado, por exemplo, por qualquer $\mathrm{PcD}$ do território da supervisão técnica, se assim fosse necessário.

Para a efetivação da coordenação do cuidado é fundamental, ainda, a comunicação entre os profissionais, gestores e usuários do serviço. A comunicação diz respeito à troca de informaçóes e ao compartilhamento de opinióes e pontos de vista, bem como envolve o estabelecimento de relaçôes de confiança, em que se torna possível a constituição de vínculo entre os envolvidos e o estabelecimento de profissionais de referência e linhas de cuidado para usuários.

Nesse sentido, a efetivação da comunicação exige um comprometimento dos profissionais com as práticas em saúde. Para Feuerwerker (2005), os trabalhadores de saúde têm sido orientados por normas e padróes de açáo que ordenam seu trabalho no SUS com poucas oportunidades de participaçáo direta na formulação de políticas e práticas, o que produz um descompasso entre as necessidades de saúde identificadas e as açóes preconizadas pela política de saúde, que ainda são centradas nos procedimentos biomédicos. Ainda, os serviços de saúde se baseiam em pessoas, trabalhadores e usuários, que possuem crenças e valores acerca do trabalho em saúde e de como ele deve ser realizado e que, portanto, são atores com intencionalidade, constroem vínculos e tais vínculos constroem a rede (FEUERWERKER, 2005). É justamente por esse aspecto que se faz fundamental compreender como se dá a comunicação interpessoal na rede de cuidado.
Ainda, Lima e Rivera (2009), Pitta e Rivera (2006) e Silva e Rocha (2014), discutem sobre necessidade de construção de novos modelos de comunicação em saúde, que promovam relaçóes mais democráticas, sinérgicas e solidárias entre os diversos atores, que compóe as redes de cuidado a saúde. Dentre as alternativas para se pensar em formas de comunicação mais democráticas, toma-se como exemplo o agir comunicativo:

[...] baseado na busca do entendimento (agir comunicativo), assentado na capacidade de os participantes da interação produzirem um consenso fundamentado argumentativamente sobre a pretensão de validez criticáveis, que irá motivar suas ações e promover a emancipação frente à dominação política e a liberação do homem para a reflexão crítica. Tal perspectiva náo elimina e nem pretende eliminar o conflito. Busca solução via uma interaçáo dialógica baseada em argumentos (LIMA; RIVERA, 2009, p. 334).

Como resultados desse estudo, os participantes assinalaram que existem falhas e descontinuidades nos processos comunicativos que comprometem o trabalho em rede, com a reprodução de um sistema fragmentado de atenção à saúde e reabilitação, composto por serviços isolados, que apresentam dificuldades em prestar assistência contínua às $\mathrm{PcD}$, gestantes, bebês de risco e demais populaçóes. Ainda, os profissionais da RC identificaram falhas importantes na comunicação entre os serviços, em que o sistema logístico - que para Mendes (2011) é um dos componentes das redes de atenção - funciona de forma irregular. Este componente deveria ser amparado por tecnologias de informaçáo, com a organização de fluxos e contrafluxos de informaçóes e pessoas nos diferentes pontos da rede de atençáo; um sistema composto por cartão de identificação dos usuários, prontuário clínico eletrônico, sistemas de acesso regulado junto aos demais serviços de saúde e sistema de transporte em saúde, o que promoveria um sistema efetivo de referência e contrarreferência.

Os resultados apontam, também, que participantes compreendem que o serviço de APS deveria ser o centro de comunicaçáo das redes, que coordenaria os fluxos e contrafluxos do sistema de saúde como um todo. Trataram também dos desafios enfrentados no cotidiano do trabalho dos serviços locais da APS que dificultam os processos comunicativos e a realização do trabalho em rede, como a sobrecarga de trabalho e problemas gerenciais. Compreende-se que a dificuldade em tratar a APS como centro integrador da rede de atenção da saúde gera, dentre outros problemas, a contratação precarizada dos 
profissionais de saúde, o fornecimento reduzido de insumos, a presença de gerências pouco efetivas, dentre outras questóes problematizadas também pelos participantes do estudo (MENDES, 2011).

Enquanto estratégia para a superação de um conjunto de desafios, a implantação do prontuário clínico eletrônico foi indicada por profissionais $\mathrm{da}$ $\mathrm{RC}$ como possibilidade de integração das informaçóes sobre os usuários entre os diferentes serviços e melhoria na qualidade da assistência. Dessa maneira, o histórico de intervençóes realizadas na APS poderia ser acessado por profissionais do hospital e vice-versa, com articulação possível também entre serviços de outros níveis de atenção. Ora, para Mendes (2011) a integração do sistema de informação promove o acesso ao histórico confiável do usuário, o que pode produzir melhores resultados na gestáo clínica realizada por diferentes profissionais em distintos serviços.

$\mathrm{Na}$ ausência de prontuários clínicos eletrônicos, profissionais da $\mathrm{RC}$ veem como alternativa a troca de informaçóes entre pontos de atenção através de correio eletrônico em que se prioriza o contato diretamente com o profissional de referência, o que tem demandado a criação de fluxos institucionais para envio e recebimento de informaçôes, pois muitas vezes o desligamento de um profissional desarticula institucionalmente as açóes. De forma semelhante, profissionais da RPCD também discutiram sobre a importância de superar a construção de uma rede de cuidado pautada principalmente nos profissionais e nas relaçôes interpessoais e a necessidade de envolver unidades e gestores na discussão sobre a melhor gestáo da comunicação.

No que se refere à organização da assistência em saúde, foi assinalada a necessidade da existência de fluxos e protocolos mais claros e flexíveis, discutidos e pactuados entre os profissionais e serviços para que possam ser adaptados a situaçóes de maior grau de complexidade ou para aquelas em que não é possível manter um itinerário pré-definido pelo sistema de saúde. Novamente, tem-se aí a articulação entre os temas do acesso, integralidade e comunicação. Para Pitta e Rivera (2006), esses produtos comunicativos, tais como protocolos e fluxos de atendimento, embora sejam muito importantes para organizar o percurso dos sujeitos na rede e a qualidade do cuidado em saúde, devem ser instituídos em conjunto com processos e estratégias criativas, pensados a partir de consensos mínimos, que, muitas vezes, estão condicionados pela incerteza, dada a complexidade das necessidades de saúde.

Assim, o desafio para integrar diversos profissionais, serviços, gestores e usuários exige açóes comunicativas, o que para Lima e Rivera (2009) só ocorrem por conta das relações interpessoais, relações interdependentes entre os pontos de cuidado na prática cotidiana dos serviços. Neste sentido, observa-se que as relaçôes interprofissionais foram exploradas como potência, em particular na RPCD, com a reflexão acerca de estratégias que evidenciam açóes comunicativas na direçáo da responsabilizaçáo pelo cuidado.

Profissionais da RC identificaram como nó crítico da rede, a falta de diálogo entre serviços e profissionais, sugerindo a promoção de "espaços de encontro" institucionalizados que garantam a participação dos trabalhadores. Já os profissionais da RPCD identificaram o Fórum de Reabilitação e demais encontros temáticos como espaço prioritário de articulação em rede, mas compartilham da preocupaçáo quanto ao alcance e a institucionalidade das discussões ocorridas neste espaço de conversação.

Portanto, fica clara a necessidade de criação de mecanismos para aprimorar a gestâo da rede e de seus processos comunicativos, o que poderia ter impactos na ampliação de açôes integrais e na garantia ao acesso às redes de atenção à saúde. Tratam-se de três temas, interligados, indicando, por um lado, a complexidade das práticas em rede e, por outro, a necessidade de açôes criativas e integradas para lidar com os desafios para a garantia do direito ao cuidado.

\section{Conclusão}

A implementação das RAS e a discussão em torno delas é ainda recente no território nacional, com experiências em curso que pretendem romper com o modelo fragmentado de assistência e oferecer uma resposta mais efetiva à construção do acesso e atenção integral, principalmente às condiçôes crônicas de saúde. Ainda que as proposiçóes presentes nas portarias das RC e RPCD busquem direcionar esforços para atençáo em rede a essas populaçóes, observa-se a existência de lacunas importantes entre o preconizado e a realidade cotidiana dos processos de trabalho nos serviços, tal como descrito para a região de saúde neste estudo.

Essas questôes colocam a importância da continuidade de políticas indutoras de reorientação da formação dos profissionais de saúde, como o PET. Nesse cenário, o PET Redes possibilitou a reflexão entre os preceptores sobre as práticas de atenção em rede à saúde e formas de qualificá-las. Vale ressaltar que o estudo se limitou a percepção dos preceptores PET e poderia ser ampliado para outros profissionais das redes de cuidado, obtendo-se, assim, uma visão dos trabalhadores em geral 
No processo de reflexão sobre o tema, foi notável a ênfase dada aos desafios para a construção do trabalho em rede no âmbito do acesso, atendimento integral e melhoria da comunicação entre profissionais e serviços que compóem as RC e RPCD. Profissionais apontaram como alternativa para lidar com a falta de acesso de PcD e bebês de risco à rede de cuidado, a expansão da Estratégia de Saúde da Família para as demais unidade básicas de saúde do território, a melhoria da mobilidade das famílias no território, apontando formas alternativas de transporte ofertadas pelo poder público e por rede de apoio social, alternativas em reabilitaçáo para o atendimento de casos crônicos, muitas vezes não elegíveis para os serviços especializados e a organização da assistência de PcD e bebês de risco a partir de suas necessidades e não apenas de critérios e fluxos pré-estabelecidos. Identifica-se a relevância de que estas sejam pensadas a partir da complexidade das situaçóes de vida, considerando-se que a oferta de serviços possa ocorrer a partir de um fluxo no território ampliado e articulado.

No que se refere à eficácia da comunicação, profissionais validaram positivamente estratégias que exploram e potencializam as relaçôes interprofissionais (comunicação através de e-mails, redes sociais, reuniốes entre serviços), porém com maior respaldo institucional em direção à responsabilização pelo cuidado. Apontou-se também a necessidade de estabelecimento e fortalecimento de fluxos e definiçóes de linhas de cuidado institucionalizadas mais flexíveis entre os diferentes serviços, com orientação da STS e pactuadas em encontros entre os profissionais em fórum de discussão, estratégia citada como forma de melhorar a comunicação entre profissionais e gestores dos serviços.

Nesse contexto, é preciso ter claro que a complexidade da produção do cuidado às distintas necessidades dos sujeitos em determinado território sempre colocará novos desafios. Nesse sentido, o estudo apontou a sensibilidade de profissionais para refletirem sobre as dificuldades enfrentadas no trabalho cotidiano e as possibilidades para sua superação. Cabe à governança da rede de cuidados, como apresentado por Mendes (2011), possibilitar um arranjo organizativo que cria uma missão e uma visão nas organizaçôes, para realizar a gestáo de todos os componentes, neste caso também das RC e RCPD. Assim, o que parece ser fundamental afirmar é que mesmo reconhecendo a importância de açôes e protocolos pactuados para a gestão de percursos de cuidado para garantir acesso e atenção integral, o horizonte indispensável nas práticas de saúde é o da produção de processos de emancipação e ampliação de participação social, garantindo, antes de tudo, o próprio direito à saúde.

\section{Referências}

ALMEIDA, M. C. Deficiência e cotidiano: reflexos e reflexóes sobre a reabilitaçáo. Revista de Terapia Ocupacional da Universidade de São Paulo, São Paulo, v. 8, n. 2/3, p. 81-86, 1997.

AMARAL, F. L. J. S. et al. Acessibilidade de PCD ou restrição permanente de mobilidade ao SUS. Ciência \& Saúde Coletiva, Rio de Janeiro, v. 17, n. 7, p. 1833-1840, 2012.

AOKI, M.; OLIVER, F. C. Pessoas com deficiência moradoras de bairro periférico da cidade de São Paulo: estudo de suas necessidades. Cadernos de Terapia Ocupacional da UFSCar, São Carlos, v. 21, n. 2, p. 391-398, 2013.

BARBOUR, R. Grupos focais. Porto Alegre: Artmed, 2009.

BRASIL. Ministério da Saúde. Secretaria de Atenção à Saúde. Portaria no 4.279, de 30 de dezembro de 2010. Estabelece diretrizes para a organização da Rede de Atençâo à Saúde no âmbito do Sistema Único de Saúde (SUS). Diário Oficial [da] República Federativa do Brasil, Poder Executivo, Brasília, DF, 31 dez. 2010.

BRASIL. Ministério da Saúde. Secretaria de Atenção à Saúde. Portaria no 1.459, de 24 de junho de 2011. Institui no âmbito do Sistema Único de Saúde - SUS - a Rede Cegonha. Diário Oficial [da] República Federativa do Brasil, Poder Executivo, Brasília, DF, 24 jun. 2011.

BRASIL. Ministério da Saúde. Secretaria de Atenção à Saúde. Portaria no 793, de 24 de abril de 2012. Institui a Rede de Cuidados à Pessoa com Deficiência no âmbito do Sistema Único de Saúde. Diário Oficial [da] República Federativa do Brasil, Poder Executivo, Brasília, DF, 24 jun. 2011.

BRASIL. Secretaria de Gestão do Trabalho e da Educação na Saúde. Edital no 14, de 8 de março de 2013. Seleção para o Programa de Educação pelo Trabalho para a Saúde/Rede de Atenção à Saúde - PET/Saúde Redes de Atenção à Saúde - 2013/2015. Diário Oficial [da] República Federativa do Brasil, Poder Executivo, Brasília, DF, 11 mar. 2013. Seção 3, p. 117. Disponível em: <http:// www.sbfa.org.br/portal/pdf/forum_348.pdf>. Acesso em: 26 mar. 2013.

BRASIL. Ministério da Saúde. Secretaria de Atenção à Saúde. Implantação das Redes de Atenção à Saúde e outras estratégias da SAS. Brasília: Ministério da Saúde, 2014. Disponível em: <http://bvsms.saude.gov.br/bvs/publicacoes/implantacao_redes_atencao_saude_sas.pdf >. Acesso em: 18 jan. 2016.

CASTRO, S. S. et al. Acessibilidade aos serviços de saúde por pessoas com deficiência. Revista de Saúde Pública, Sáo Paulo, v. 45, n. 1, p. 99-105, 2011. 
FEUERWERKER, L. Modelos tecnoassistenciais, gestão e organização do trabalho em saúde: nada é indiferente no processo de luta para consolidação do SUS. Interface - Comunicação, Saúde, Educação, Botucatu, v. 9, n. 18, p. 489-506, 2005.

GONÇALVES, C. R. et al. Recursos humanos: fator crítico para as redes de atenção à saúde. Saúde Debate, Rio de Janeiro, v. 38, n. 100, p. 26-34, 2014.

KASSOUF, A. L. Acesso aos serviços de saúde nas áreas urbanas e rural do Brasil. Revista de Economia e Sociologia Rural, Brasília, v. 43, n. 1, p. 29-44, 2005.

LIMA, J. C.; RIVERA, F. J. U. Agir comunicativo, redes de conversação e coordenação em serviços de saúde: uma perspectiva teórico-metodológica. Interface - Comunicação, Saúde, Educação, Botucatu, v. 13, n. 31, p. 329-342, 2009.

MARSIGLIA, R. M. G. Universalização do acesso ao Sistema Único de Saúde no Brasil: desafios para a Atenção Primária à Saúde. Cadernos de Terapia Ocupacional da UFSCar, São Carlos, v. 20, n. 3, p. 317-325, 2012.

MATTOS, R. A. Os sentidos da integralidade: algumas reflexóes acerca dos valores que merecem ser defendidos. In: PINHEIRO, R.; MATTOS, R. A. (Org.). Os sentidos da integralidade na atenção e no cuidado à saúde. Rio de Janeiro: IMS- UERJ/ABRASCO, 2001. p. 39-64

MENDES, E. V. As redes de atenção à saúde. Brasília: Organizaçáo Pan-Americana da Saúde, 2011.

MENDES, E. V. As redes de atenção à saúde. Ciência \& Saúde Coletiva, Rio de Janeiro, v. 15, n. 5, p. 2297 2305, 2010.

MINAYO, M. C. O. Desafio do conhecimento: pesquisa qualitativa em saúde. São Paulo: Hucitec, 2007.

OTHERO, M. B. Atenção à saúde da pessoa com deficiência: necessidades sob a perspectiva dos sujeitos. 2010. 331 f. Dissertação (Mestrado em Medicina Preventiva) - Universidade de São Paulo, São Paulo, 2010.

PAN AMERICAN HEALTH ORGANIZATION PAHO; WORLD HEALTH ORGANIZATION WHO. Primary Health Care in the Americas: a position paper of the Pan American Health Organization/World Health Organization (PAHO/WHO). Washington: PAHO, 2007. Disponível em: <http://bvsms.saude. gov.br/bvs/saudelegis/gm/2012/prt0793_24_04_2012. html>. Acesso em: 2 fev. 2016.

PIMENTEL, A. M. et al. Terapia Ocupacional na Atenção Básica: a construção de uma prática. Revista de Terapia Ocupacional da Universidade de São Paulo, São Paulo, v. 22, n. 2, p. 110-116, 2011.

PITTA, A. M. R.; RIVERA, F. J. U. Sobre pontos de partida: planejamento em comunicação e integralidade da atenção em saúde. Inteface - Comunicação, Saúde, Educação, Botucatu, v. 10, n. 20, p. 395-410, 2006.

SANTARPIO, A. F. R.; CAVALCANTI, A.; ALVES, A. L. O direito de ir e vir: a acessibilidade do transporte pú- blico. Cadernos de Terapia Ocupacional da UFSCar, São Carlos, v. 23, n. 4, p. 775-780, 2015.

SÃO PAULO. Secretaria Municipal da Saúde. Rede de cuidado à pessoa com deficiência RRAS - 06. São Paulo: Secretaria Municipal da Saúde, 2013a. Disponível em: <http://www.prefeitura.sp.gov.br/cidade/secretarias/ upload/saude/PlanodeacaoRedePessoacomDeficiencia. pdf>. Acesso em: 2 fev. 2016.

SÃO PAULO. Secretaria Municipal da Saúde. Assessoria técnica de tecnologia da informação. São Paulo: Secretaria Municipal da Saúde, 2013b. Disponível em: <http:// intranet.saude.prefeitura.sp.gov.br/areas/atti/noticias/ paginas/ATTI-Descritivo\%20SIGA-Saude\%20-\%20 2013.pdf>. Acesso em: 26 mar. 2016.

SHIMIZU, H. E. Percepção dos gestores do Sistema Único de Saúde acerca dos desafios da formação das Redes de Atenção à Saúde no Brasil. Physis: Revista de Saúde Coletiva, Rio de Janeiro, v. 23, n. 4, p. 1101-1122, 2013.

SILVA, S. F. Organizaçáo de redes regionalizadas e integradas de atençáo à saúde: desafios do Sistema Único de Saúde (Brasil). Ciência \& Saúde Coletiva, Rio de Janeiro, v. 16, n. 6, p. 2753-2762, 2011.

SILVA, V. C.; ROCHA, C. M. F. A comunicação em saúde no sistema único de saúde: uma revisão de literatura. In: FERLA, A. A.; ROCHA, C. M. F. Fazeres em Saúde Coletiva: experiências e reflexóes de jovens sanitaristas. Porto Alegre: Rede Unida, 2014. p. 133-143. Disponível em: <http://www.redeunida.org.br/editora/ biblioteca-digital/colecao-cadernos-de-saude-coletiva/ cadernos-da-saude-coletiva-fazeres-em-saude-coletiva-experiencias-e-reflexoes-de-jovens-sanitaristas-vol-3-pdf>. Acesso em: 14 jan. 2016.

SOUZA, C. C. B. X.; ROCHA, E. F. Portas de entrada ou portas fechadas? $\mathrm{O}$ acesso à reabilitação nas Unidades Básicas de Saúde da região sudeste do município de São Paulo - período de 2000 a 2006. Revista de Terapia Ocupacional da Universidade de São Paulo, São Paulo, v. 21, n. 3, p. 230-239, 2010.

SOUZA, F. R.; GOMES, M. L.; AOKI, M. Terapia ocupacional na Atenção Primária à Saúde: reflexôes sobre as populaçóes atendidas. Cadernos de Terapia Ocupacional da UFSCar, São Carlos, v. 20, n. 3, p. 341-350, 2012.

SOUZA, F. R.; PIMENTEL, A. M. Pessoas com deficiência: entre necessidades e atenção à saúde. Cadernos de Terapia Ocupacional da UFSCar, São Carlos, v. 20, n. 2 , p. 229-237, 2012

STARFIELD, B. Atenção Primária: equilíbrio entre necessidades de saúde, serviços e tecnologia. Brasília: UNESCO, Ministério da Saúde, 2002.

WORLD HEALTH ORGANIZATION - WHO. Integrated health services - what and why? Geneva: WHO, 2008. (Technical Brief, 1). Disponível em: <http://www. who.int/healthsystems/technical_brief_final.pdf $>$. Acesso em: 1 ago. 2016. 


\section{Contribuição dos Autores}

Marta Aoki e Marina Picazzio Perez Batista: concepção do texto, coleta, tratamento e análise das informações, organização de fontes, redação e revisão final do texto. Fátima Corrêa Oliver, Maria Helena Morgani de Almeida e Daniela Molini-Avejonas: orientação e revisão final do texto. Todos os autores aprovaram a versão final do texto.

\section{Fonte de Financiamento}

\section{FAPESP.}

\section{Notas}

${ }^{1}$ O SIGA (Sistema Integrado de Gestão e Assistência em Saúde) gerencia fluxos e serviços oferecidos pela rede de cuidado a saúde (SÃO PAULO, 2013b).

2 É uma modalidade de transporte porta a porta, destinado às pessoas com deficiência física com alto grau de severidade e dependência, gratuito aos seus usuários, oferecido pela Prefeitura do Município de São Paulo. 